\title{
Bendiocarb resistance in Anopheles gambiae s.l. populations from Atacora department in Benin, West Africa: a threat for malaria vector control
}

\author{
Rock Aïkpon ${ }^{1,2^{*}}$, Fiacre Agossa ${ }^{1,2}$, Razaki Ossè ${ }^{1,2}$, Olivier Oussou ${ }^{1}$, Nazaire Aïzoun ${ }^{1,2}$, Frédéric Oké-Agbo \\ and Martin Akogbéto ${ }^{1,2}$
}

\begin{abstract}
Background: Owing to pyrethroid resistance in An. gambiae, the carbamate and organophosphate insecticides are currently regarded as alternatives or supplements to pyrethroids for use on mosquito net treatments. Resistance monitoring is therefore essential to investigate the susceptibility of An. gambiae s.l to these alternative products.

Methods: Two to three day old adult female Anopheles mosquitoes were reared from larvae collected in the five districts (Kouandé, Natitingou, Matéri, Péhunco, Tanguiéta) of the Atacora department. Mosquitoes were then exposed to WHO impregnated papers. The four treatments consisted of: carbamates $(0.1 \%$ bendiocarb, $0.1 \%$ propoxur) and organophosphates (0.25\% pirimiphosmethyl, $1 \%$ fenitrothion). PCR assays were run to determine the members of the An. gambiae complex, the molecular forms (M) and (S), as well as phenotypes for insensitive acetylcholinesterase (AChE1) due to ace- $1^{R}$ mutation.

Results: Bioassays showed bendiocarb resistance in all populations of An. gambiae s.s. tested. Propoxur resistance was observed in Matéri, Péhunco and Tanguiéta, while it was suspected in Kouandé and Natitingou. As for the organophosphates, susceptibility to pirimiphos-methyl was assessed in all populations. Fenitrothion resistance was detected in Kouandé, Péhunco and Tanguiéta, while it was suspected in Matéri and Natitingou. The S-form was predominant in tested samples (94.44\%). M and S molecular forms were sympatric but no M/S hybrids were detected. The ace $-1^{R}$ mutation was found in both $\mathrm{S}$ and $\mathrm{M}$ molecular forms with frequency from 3.6 to $12 \%$. Although the homozygous resistant genotype was the most prevalent genotype among survivors, the genotypes could not entirely explain the bioassay results.

Conclusion: Evidence of bendiocarb resistance in An. gambiae populations is a clear indication that calls for the implementation of insecticide resistance management strategies. The ace- $1^{R}$ mutation could not entirely explain the resistance to bendiocarb observed and is highly suggestive of involvement of other resistance mechanisms such as metabolic detoxification.
\end{abstract}

Keywords: Bendiocarb resistance, Anopheles gambiae, Threat, Malaria vector control, Benin

\footnotetext{
* Correspondence: rockypremier@yahoo.fr

'Centre de Recherche Entomologique de Cotonou (CREC), 06 BP 2604, Cotonou, Bénin

${ }^{2}$ Faculté des Sciences et Techniques, Université d'Abomey Calavi, Calavi, Bénin
}

\section{Biomed Central}

(c) 2013 Aïkpon et al.; licensee BioMed Central Ltd. This is an Open Access article distributed under the terms of the Creative Commons Attribution License (http://creativecommons.org/licenses/by/2.0), which permits unrestricted use, distribution, and reproduction in any medium, provided the original work is properly cited. 


\section{Background}

Malaria is a major public health problem and Anopheles gambiae is one of the major vectors of this disease in sub-Saharan Africa [1]. The current effective vector control tools include the use of Long Lasting Insecticide Nets (LLIN) and Indoor Residual Spraying (IRS) [2]. In sub-Sahara Africa and southern Asia, these two methods have shown good results $[3,4]$.

Pyrethroids are the only group of insecticides currently recommended for net treatment, the others (organochlorine, carbamate and organophosphate) are applied for IRS $[5,6]$. The main problem with ITNs and IRS is the development of insecticide resistance, particularly pyrethroid-resistance by several populations of Anopheles gambiae [7-10]. Prior to the present study, a monitoring survey was carried out on pyrethroid resistance from January to October 2012 in the department of Atacora and showed a high level of $k d r$ allelic frequency of $81.78 \%$ on average. The $k d r$ mutation was found in both $\mathrm{S}$ (92.02\%) and M (30.25\%) molecular forms (Aïkpon, personal communication). More recently, the emergence of resistance in populations of An. gambiae to common classes of insecticides used in public health has been reported in many countries in Africa, including Côte d'Ivoire [7,11], Kenya [12], Benin [13,14], Niger [15], Burkina Faso [16], Mali [17], Nigeria [18,19], South Africa [20] and Cameroon [21].

With the widespread resistance to pyrethroids, the carbamate class of insecticides is one of the possible alternatives that can be considered effective enough to combat pyrethroid-DDT resistance, mainly because of its different mode of action. For this reason, Benin Republic adopted a national malaria control strategy based on large-scale integrated control measures, which included Insecticide Treated Nets (ITNs) and Indoor Residual Spraying (IRS) using bendiocarb, a carbamate insecticide. The department of Atacora has housed a large scale IRS campaign since 2011. However, there is not sufficient information on the resistance status of carbamate insecticides in the field populations of An. gambiae s.l. in North West Benin.

The aim of this study is to provide information on the susceptibility status of An. gambiae s.l. to carbamate that has been used in vector control in Benin and also to investigate the possibility of co-resistance with organophosphates in the same population of An. gambiae s.l. It is hoped that findings from this study will promote and improve effective vector control decision making.

\section{Methods}

\section{Study area}

The study was carried out in Atacora, a department located in the north-west of Benin and includes five districts: Kouandé, Matéri, Natitingou, Péhunco and
Tanguiéta (Figure 1). The five districts covered $13,778 \mathrm{~km}^{2}$ and an estimated 482,080 populations in 2012. Atacora region has a sub-equatorial type climate with only one dry season (December-May) and only one rainy season (JulyNovember). The annual mean rainfall is $1,300 \mathrm{~mm}$ and the mean monthly temperature varies between $22^{\circ} \mathrm{C}$ and $33^{\circ} \mathrm{C}$. The department is irrigated by three major rivers: the Mekrou, the Pendjari and the Alibori. The major economic activity is agriculture and it is characterized by the production of cotton and millet where various classes of pesticides are used for pest control. From 2011 onwards the department has conducted a large scale Indoor Residual Spraying (IRS) campaign and free distribution of ITNs.

\section{Mosquito collections}

Anopheles gambiae s.l. larvae were collected in 5 districts and in each district, four villages were selected randomly. At each locality chosen, Anopheline larvae were collected from various natural breeding sites including ground pools, gutters, puddles and abandoned potholes, during the rainy season from July to October 2012. Water was scooped using a plastic scoop and poured into small transparent plastic bowls. A strainer was used to sieve and pool together the third and fourth instar larvae in order to have sufficient adult emergence of the same physiological age. The mosquito larvae collected were transported in well labeled plastic bottles to the laboratory of the Centre de Recherche Entomologique de Cotonou, Benin (CREC) where they were maintained at $28 \pm 2 \mathrm{C}$ and $72 \pm 5 \%$ relative humidity. A laboratory susceptible strain of An. gambiae Kisumu was used as a reference strain to compare the susceptibility levels of the field populations.

\section{Insecticide susceptibility tests}

Mosquitoes collected were assayed using WHO discriminating dosages with four insecticides of technical grade quality: two carbamates $(0.1 \%$ bendiocarb, $0.1 \%$ propoxur) and two organophosphates ( $0.25 \%$ pirimiphos méthyl, $1 \%$ fenitrothion). Four batches of 25 unfed females, aged 2-5 days, were exposed to the diagnostic doses of insecticide treated papers for $60 \mathrm{~min}$ at $27 \pm 1^{\circ} \mathrm{C}$ and $80 \%$ relative humidity. The twenty-five females of An. gambiae were introduced into each tube and monitored at different time intervals $(10,15,20,30,45,60$ minutes), the number "knocked-down" were recorded. After one hour exposure, mosquitoes were transferred into holding tubes and provided with cotton wool saturated with a $10 \%$ honey solution. Batches exposed to untreated papers were used as control. Mortalities were recorded after 24 hours and the susceptibility status of the population was graded according to the WHO protocol [22]. Dead and surviving mosquitoes from this 


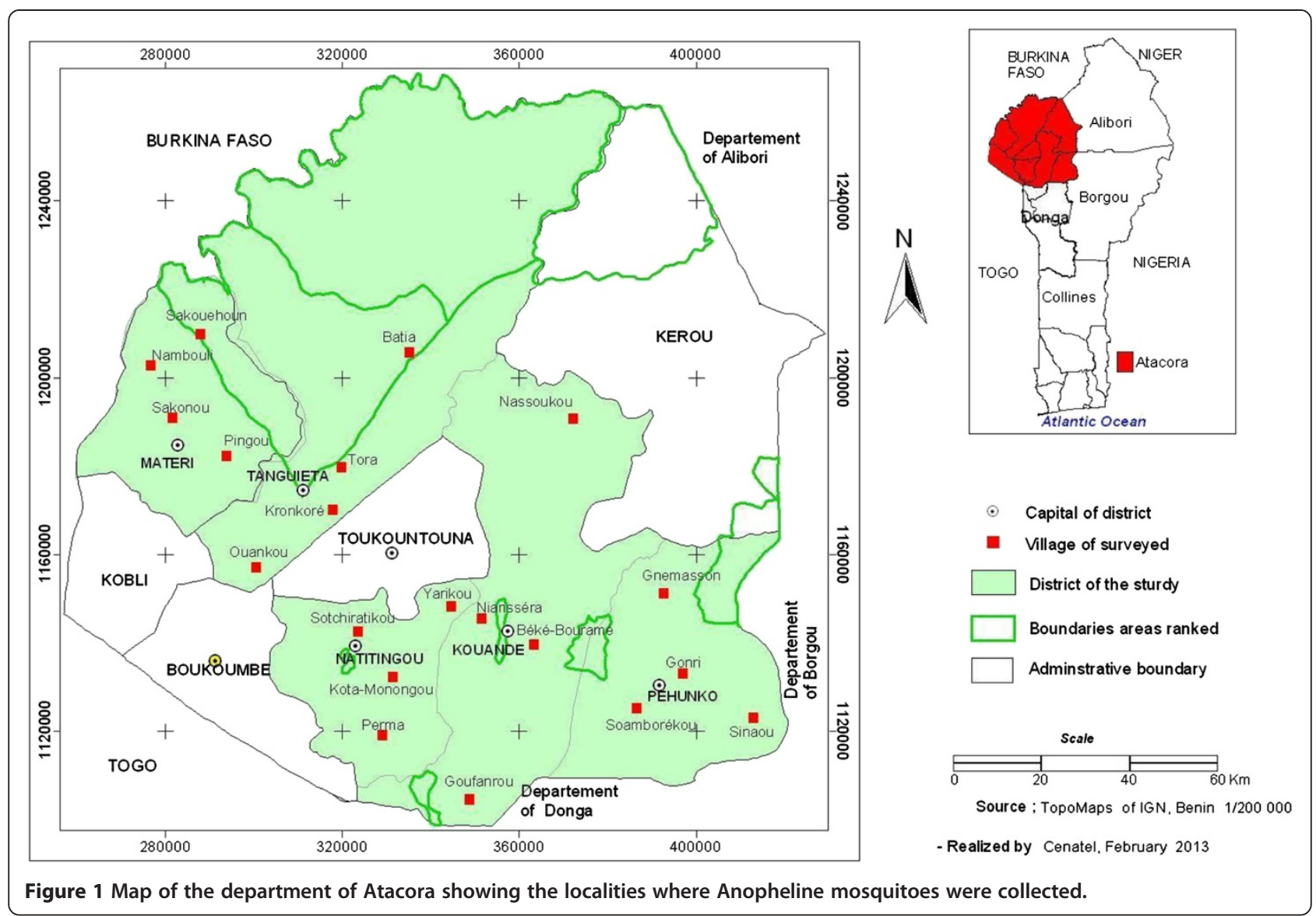

bioassay were kept separately in eppendorf tubes containing silica gel and stored at $-20^{\circ} \mathrm{C}$ for further molecular analysis.

\section{Species identification and PCR detection of Ace- $1^{R}$ mutation}

Live and dead specimens of An. gambiae from the bioassay tests were subjected to the An. gambiae species specific PCR assays for species identification [23]. Aliquots of DNA extracted from PCR positive specimens of An. gambiae s.s. were subjected to PCR assays for identification of the molecular ' $M$ ' and ' $S$ ' forms [24].

The PCR-RFLP diagnostic test was used to detect the presence of G119S mutation (ace. $1^{R}$ gene). Mosquito genomic DNA was amplified using the primers Ex3AGdir 5' GATCGTGGACACCGTGTTCG3' and Ex3AGrev 5'AG GATGGCCCGCTGGAACAG3' according to [25]. One microlitre of total DNA extracted from a single mosquito was used as a template in a $25 \mathrm{ml}$ PCR reaction containing Taq DNA polymerase buffer, $0.2 \mathrm{mM}$ dNTP and $10 \mathrm{pmol}$ of each primer. The PCR conditions were $94^{\circ} \mathrm{C}$ for $5 \mathrm{~min}$ and then 35 cycles of $\left(94^{\circ} \mathrm{C}\right.$ for $30 \mathrm{~s}, 54^{\circ} \mathrm{C}$ for $30 \mathrm{~s}$ and $72^{\circ} \mathrm{C}$ for $30 \mathrm{~s}$ ) with a final $5 \mathrm{~min}$ extension at $72^{\circ} \mathrm{C}$. Fifteen microlitres of PCR product were digested with $5 \mathrm{U}$ of AluI restriction enzyme (Promega) in a final volume of $25 \mathrm{ml}$.
The PCR fragments were fractionated on a $2 \%$ agarose gel stained with ethidium bromide and visualized under UV light.

\section{Data analysis}

The resistant status of mosquito samples was determined according to the WHO criteria [22]:

- Mortality rate is $>98 \%$ : the population was considered fully susceptible

- Mortality rates ranged between 90 - 98\%: resistance suspected in the population

- Mortality rates $<90 \%$, the population was considered resistant to the tested insecticides

To compare the status of insecticide resistance, Fisher's exact test was carried out to determine if there was any significant difference between mortality rates of populations of An. gambiae s.s. of districts using Statistica 6.0. Allelic frequencies of G119S mutation were analysed using the version 1.2 of Genepop [26]. To assess if the mutation frequencies were identical across populations, the test of genotypic differentiation was performed [27]. 


\section{Results}

Susceptibility to carbamates and organophosphates

Mortality rates of the Kisumu reference strain to all insecticides was $100 \%$ (Table 1). In contrast, all the field samples (Kouandé, Matéri, Natitingou, Péhunco and Tanguiéta) were resistant to carbamates, with mortality rates less than $80 \%$ for bendiocarb. Propoxur resistance was observed in Matéri, Péhunco and Tanguiéta, with 79$89 \%$ mortality rates, while it was suspected in Kouandé and Natitingou with $90-91 \%$ mortality rate. As for the organophosphates, susceptibility to pirimiphos-methyl was assessed on all populations with mortality rates higher than 98\%. Fenitrothion resistance was detected in Kouandé, Péhunco and Tanguiéta, with 83-90\% mortality rates, while it was suspected in Matéri and Natitingou with 94-95\% mortality rates.

\section{Molecular forms and frequencies of the ace $-1^{R}$ mutation}

All PCR analysis identifying An. gambiae s.l. species realized in this study showed that all mosquitoes belonging to An. gambiae s.l. were An. gambiae s.s. Two hundred and fifty-two mosquitoes were identified to molecular forms and analyzed for the ace. $1^{R}$ mutation; results are shown in Table 2. The $\mathrm{M}$ and $\mathrm{S}$ molecular forms of $A n$. gambiae s.s. occurred in sympatry in Kouandé, Matéri, Natitingou and Tanguiéta districts. However, the S-form was predominant, representing $94.44 \%$ of the whole sample $(n=252)$. No heterozygote M/S molecular form was found. The ace- $1^{R}$ mutation was detected in all the districts, either in the $\mathrm{M}$ or in the $\mathrm{S}$ form. It was detected both in the homozygous and heterozygote state in $\mathrm{S}$ form, but only in the heterozygote state in $M$ form with only one individual mutant. So, the highest mutation frequency was observed in the $S$ form (12\%) and the lowest in the $M$ (3.6\%). No significant difference was seen between ace. $1^{R}$ mutation frequencies in the districts in addition, no significant difference was seen between ace. $1^{R}$ mutation frequencies in $\mathrm{M}$ and $\mathrm{S}$ forms $(\mathrm{p}=0.2327)$.

\section{Role of ace- $1^{R}$ mutation in providing bendiocarb} resistance

To assess the role of the ace- $1^{R}$ allele in conferring bendiocarb resistance in $A n$. gambiae S.s., the ace- $1^{R}$ genotype was determined for dead and alive mosquitoes detected in the WHO bioassay using bendiocarb (Figure 2). Among both bioassay survivors and non-survivors, all ace $-1^{R}$ genotypes (RR, RS and SS) were found. However, the homozygous resistant genotype $R R$ was only found among the bioassay survivors, and the heterozygote genotype RS was the most prevalent genotype among the bioassay survivors.

Although there was a significant $a c e-1^{R}$ genotype differentiation between bioassay survivors and non-survivors ( $<<0.0001$ ), homozygous susceptible mosquitoes were found among bioassay survivors.

\section{Discussion}

Information on the resistance status of the main malaria vectors is essential to guide the choice of insecticides for use by The National Malaria Control Programme. Indeed, since 2011, the NMCP of Benin has implemented a large IRS campaign using bendiocarb in the department of Atacora. There is,therefore, the need to closely monitor insecticide resistance and bendiocarb resistance especially in malaria control programmes which rely solely on ITNs and IRS interventions in Benin. Moreover, very little data is available on the status of $A n$. gambiae resistance to carbamates and organophosphates in the department of Atacora.

Results of this study showed that field populations of An. gambiae collected from five districts of the department of Atacora developed resistance to bendiocarb, propoxur, and fenitrothion but not to pirimiphosmethyl. This is the first time that bendiocarb resistance has been reported in Benin. Indeed, previous studies in the department of Atacora reported that An. gambiae were susceptible to bendiocarb in 2010 and justified its

Table 1 Mortality of a susceptible strain (Kisumu) and wild populations of Anopheles gambiae s.s. exposed to diagnostic doses of technical material of insecticides

\begin{tabular}{|c|c|c|c|c|c|c|c|c|}
\hline \multirow[t]{2}{*}{ Localities } & \multicolumn{2}{|c|}{ Bendiocarb 0.1\% } & \multicolumn{2}{|c|}{ Propoxur $0.1 \%$} & \multicolumn{2}{|c|}{ Pirimiphos-méthyl $0.25 \%$} & \multicolumn{2}{|c|}{ Fenitrothion $1 \%$} \\
\hline & $\%$ Mortality & Status & $\%$ Mortality & Status & $\%$ Mortality & Status & $\%$ Mortality & Status \\
\hline Kisumu & 100(103) & $\mathrm{S}$ & $100(102)$ & $\mathrm{S}$ & $100(99)$ & $\mathrm{S}$ & $100(104)$ & $\mathrm{S}$ \\
\hline Kouandé & $78.89^{\mathrm{a}}(90)$ & $\mathrm{R}$ & $90^{\mathrm{a}}(60)$ & RS & $100^{\mathrm{a}}(81)$ & S & $87.8^{\mathrm{a}}(82)$ & $\mathrm{R}$ \\
\hline Matéri & $58.9^{b}(73)$ & $R$ & $89^{\mathrm{a}}(70)$ & $\mathrm{R}$ & $100^{\mathrm{a}}(72)$ & S & $94.79^{\mathrm{a}}(96)$ & RS \\
\hline Natitingou & $61.9^{b}(84)$ & $R$ & $91^{\mathrm{a}}(62)$ & RS & $100^{\mathrm{a}}(58)$ & S & $95^{\mathrm{a}}(70)$ & RS \\
\hline Péhunco & $79.21^{\mathrm{a}}(101)$ & $\mathrm{R}$ & $79.69^{\mathrm{a}}(64)$ & $\mathrm{R}$ & $98.88^{\mathrm{a}}(89)$ & S & $89.89^{\mathrm{a}}(89)$ & $\mathrm{R}$ \\
\hline Tanguiéta & $63.21^{\mathrm{b}}(106)$ & $\mathrm{R}$ & $88.13^{\mathrm{a}}(59)$ & $\mathrm{R}$ & $100^{\mathrm{a}}(90)$ & S & $83.67^{\mathrm{a}}(49)$ & $\mathrm{R}$ \\
\hline
\end{tabular}

Number of tested mosquitoes in parentheses; \% Mortality: Mortality rate $24 \mathrm{~h}$ post exposure; S: indicates susceptibility; R: suggests resistance; RS: resistance suspected. NB: Numbers in the same column with the same superscript do not differ significantly by Fisher's exact test $(p>0.05)$. 
Table 2 Acetylcholinesterase phenotypes and frequency of ace- $1^{R}$ mutation in the molecular $M$ and $S$ forms of Anopheles gambiae s.s

\begin{tabular}{|c|c|c|c|c|c|c|c|c|}
\hline \multirow[t]{3}{*}{ Localities } & \multicolumn{4}{|c|}{ S Form } & \multicolumn{4}{|c|}{ M Form } \\
\hline & \multicolumn{3}{|c|}{ Phénotypes } & \multirow[t]{2}{*}{$f(a c e-1)$} & \multicolumn{3}{|c|}{ Phénotypes } & \multirow[t]{2}{*}{$\mathrm{f}($ ace -1$)$} \\
\hline & RR & $\mathrm{RS}$ & SS & & $\mathrm{RR}$ & $\mathrm{RS}$ & SS & \\
\hline Kouandé & 1 & 10 & 47 & $0,103^{a}$ & 0 & 0 & 3 & 0 \\
\hline Matéri & 2 & 6 & 36 & $0,114^{a}$ & 0 & 0 & 4 & 0 \\
\hline Natitingou & 0 & 11 & 33 & $0,125^{a}$ & 0 & 0 & 1 & 0 \\
\hline Péhunco & 1 & 11 & 37 & $0,133^{a}$ & 0 & 0 & 0 & - \\
\hline Tanguiéta & 0 & 11 & 32 & $0,128^{a}$ & 0 & 1 & 5 & 0,083 \\
\hline Total & 4 & 49 & 185 & 0,12 & 0 & 1 & 13 & 0,036 \\
\hline
\end{tabular}

${ }^{a}$ Values sharing a superscript letter are not significantly different at the $5 \%$ level for G119S mutation distribution.

choice in IRS in this department (Aïkpon, personal communication). Akogbeto et al. [28] and Padonou et al. [29] reported this susceptibility of An. gambiae to bendiocarb in southern Benin. Moreover, An. gambiae displayed large variations in resistance levels to carbamates and organophosphates. Although the wild populations were all resistant to bendiocarb, resistance was less marked to propoxur and fenitrothion, at WHO diagnostic concentrations. However, all these populations were very susceptible to pirimiphos-methyl. The high resistance of the mosquito population to bendiocarb would be due to the strong selective pressure that represents the use of insecticides in households for public health purposes, notably IRS using bendiocarb and massive quantities of carbamates and organophosphates in agricultural settings in the department of Atacora. Indeed, in the cotton growing areas in Atacora, farmers use huge amounts of insecticides to avoid substantial yield reduction of their crops. Several studies showed that agricultural practices seem to have contributed to the emergence of insecticide resistance in Anopheles populations [10,14,30].

The development of resistance by the mosquito population to bendiocarb could jeopardize the current malaria control programme, specifically IRS using bendiocarb that is currently underway in the department of Atacora.

Cross-resistance to organophosphates and carbamates suggests the involvement of their common target site: AChE-1 [31]. Indeed, the ace- $1^{R}$ mutation was identified in all districts although its frequency remains relatively low, and agrees with previous findings that reported ace$1^{R}$ mutation in Benin [32].

In this study, the distribution of $\mathrm{M}$ and $\mathrm{S}$ molecular forms of An. gambiae s.s. agrees with previous findings in Benin that reported both $\mathrm{M}$ and $\mathrm{S}$ forms with the predominance of $\mathrm{S}$ forms in a savannah areas [33]. The presence of ace- $1^{R}$ mutations in both $\mathrm{M}$ and $\mathrm{S}$ forms of An. gambiae s.s. has already been reported by Weill

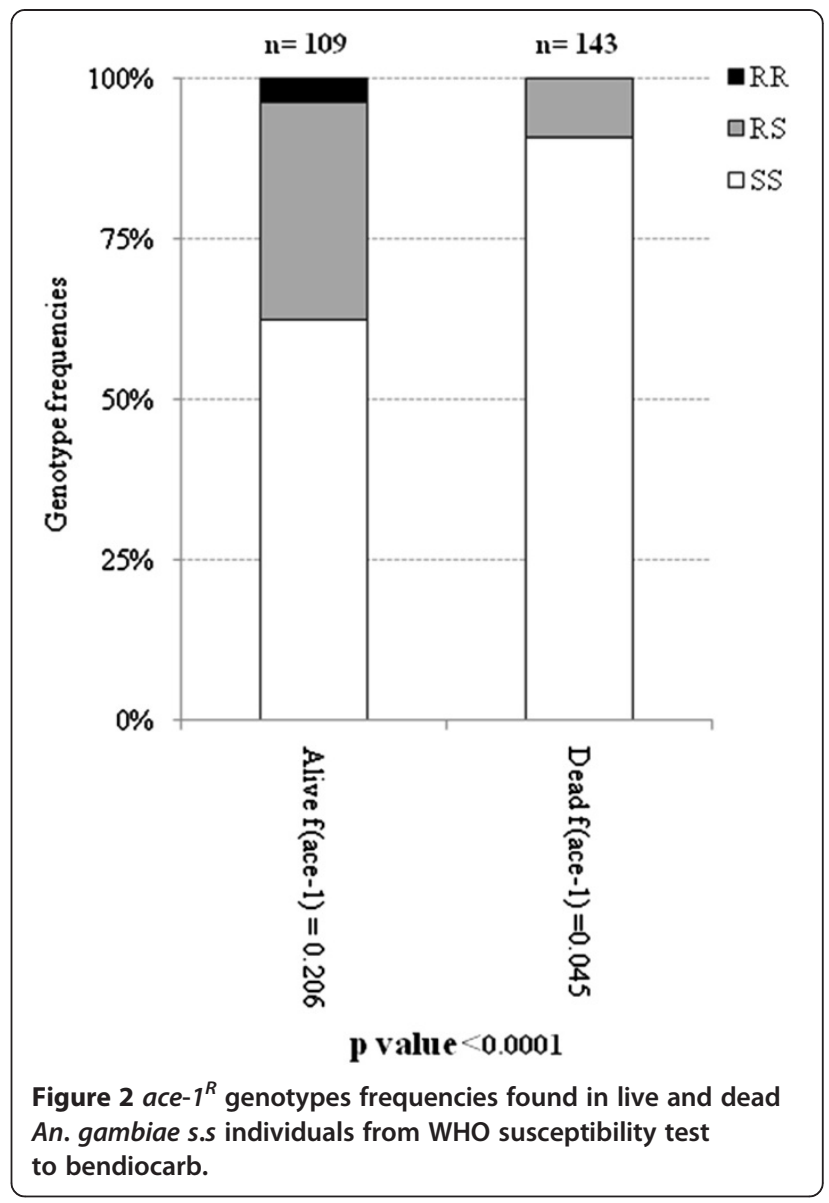

et al. [31] and Djogbénou et al. [32] and was suggested to result from introgression between forms. However, the ace- $1^{R}$ mutation frequency was higher in the $\mathrm{S}$ form. The low number of homozygous resistant individuals might be related to high fitness cost of the ace $-1^{R}$ mutation, resulting in death of the homozygous resistant mosquitoes $[31,34,35]$. The high number of heterozygous resistant $\mathrm{RS}$ is also in agreement with previous studies that noticed that in areas where the resistant allele $a c e-1^{R}$ is present, resistant mosquitoes will mainly be in the heterozygote state (RS) $[11,35]$.

Moreover, the role of ace- $1^{R}$ mutation in conferring bendiocarb resistance was assessed. The WHO bioassays performed on An. gambiae s.s. from the study area showed that the homozygous resistance was found only among bioassay survivors, however, the homozygous susceptible genotype (SS) is the most prevalent genotype among these survivors. The high proportion of homoygous susceptible specimens, which survived the WHO bioassays, added to the low rate of ace- $1^{R}$ allele frequency may suggest the implication of biochemical resistance mechanisms.

Further investigation is needed to evaluate the biochemical mechanism that could be involved in the 
resistance of An. gambiae to carbamates and organophos phates and better understand the difference in resistance between the carbamates and organophosphates.

\section{Conclusion}

The present study provides useful information on the susceptibility of An. gambiae to carbamates and organophosphates. It showed that An. gambiae has developped a resistance to bendiocarb that can be a threat for malaria vector control in Benin. Hence, there is a need to implement vector resistance management approches to malaria vector control in Benin.

\section{Competing interests}

The authors declare that they have no competing interests.

\section{Author's contributions}

$\mathrm{RA}, \mathrm{FA}, \mathrm{RO}, \mathrm{OO}, \mathrm{NA}, \mathrm{FOA}$ and MA designed the study. RA, OO, NA and MA carried out the field activities. RA drafted the manuscript and analyzed the data. FA, RO and FOA critically revised the manuscript. MA conceived and designed the study and revised the manuscript for intellectual content. All authors read and approved the final manuscript.

\section{Acknowledgements}

This work was financially supported by PMI (President's Malaria Initiative) through USAID. We thank the Ministry of Higher Education and Scientific Research (MESRS) and the team of CREC for their technical assistance during field work. We also thank the people of Atacora for their collaboration.

Received: 29 May 2013 Accepted: 22 June 2013

Published: 26 June 2013

\section{References}

1. Gillies MT, Coetzee M: A supplement to the Anophelinae Africa South of the Sahara (Afrotropical region), Johannesburg, South Africa. S Afr Inst Med Res 1987, 55:1-143.

2. Beier JC, Keating J, Githure JI, Macdonald MB, Impoinvil DE, Novak RJ: Integrated vector management for malaria control. Malaria J 2008, 7(supp 1):54

3. Curtis CF, Abraham E, Mnzava P: A comparison of use of a pyrethroid either for house spraying or for bednet treatment against malaria vectors. Trop Med Int Health 1998, 3:619-631.

4. Rowland M: Malaria control: bednets or spraying? Malaria control in the Afghan refugee camps of western Pakistan. Trans $R$ Soc Trop Med Hyg 1999, 93:458-459.

5. Guillet P, Chandre F, Mouchet J: L'utilisation des insecticides en santé publique: état et perspectives. Med Mal Infect 1997, 27:552-557.

6. Devine GJ, Ogusuku E: Adaptability is key when monitoring insecticide resistance. Bull World Health Organ 2009, 87:887.

7. Elissa N, Mouchet J, Riviere F, Meunier JY, Yao K: Resistance of Anopheles gambiae s.s. to pyrethroids in Côte-d'Ivoire. Ann Soc Belge Med Trop 1993, 73:291-294

8. Akogbéto M, Yakoubou S: Résistance des vecteurs du paludisme vis-à-vis des pyréthrinoïdes utilisés pour l'imprégnation des moustiquaires au Bénin, Afrique de l'Ouest. Bull Soc Pathol Exot 1999, 92:123-130.

9. Chandre F, Darriet F, Duchon S, Finot L, Manguin S, Carnevale P, Guillet P: Modifications of pyrethroid effects associated with kdr mutation in Anopheles gambiae. Med Vet Entomol 2000, 14:81-88.

10. Akogbeto M, Djouaka RF, Kinde-Gazard DA: Screening of pesticide residues in soil water samples from agricultural settings. Malaria J 2006, 5:22.

11. Ahoua-Alou LP, Koffi AA, Adja MA, Tla E, Kouassi PK, Kone M, Chandre F: Distribution of ace- $1 R$ and resistance to carbamates and organophosphates in Anopheles gambiae s.s. populations from Côte d'Ivoire. Malaria J 2010, 9:167.

12. Vulule JM, Beach RF, Atieli FK, MCAllister JC, Brogdon WG, Roberts JM, Mwangi RW, Hawley WA: Elevated oxidase and esterase levels associated with permethrin tolerance in Anopheles gambiae from Kenyan villages using permethrin impregnated nets. Med Vet Entomol 1999, 13:239-244.

13. Corbel V, N'Guessan R, Brengues C, Chandre F, Djogbenou L, Martin T, Akogbeto M, Hougard JM, Rowland M: Multiple insecticide resistance mechanisms in Anopheles gambiae and Culex quinquefasciatus from Benin, West Africa. Acta Trop 2007, 101:207-216.

14. Yadouleton AW, Asidi A, Djouaka RF, Braïma J, Agossou CD, Akogbeto MC: Development of vegetable farming: a cause of the emergence of insecticide resistance in populations of Anopheles gambiae in urban areas of Benin. Malaria J 2009, 8:103.

15. Czeher C, Labbo R, Arzika I, Duchemin JB: Evidence of increasing Leu-Phe knockdown resistance mutation in Anopheles gambiae from Niger following a nationwide longlasting insecticide-treated nets implementation. Malaria J 2008, 7:189.

16. Diabate A, Baldet T, Chandre F, Guiguemde RT, Brengues C, Guillet P, Hemingway J, Hougard JM: First report of the kdr mutation in Anopheles gambiae M form from Burkina Faso, West Africa. Parassitologia 2002, 44:157-158

17. Fanello C, Petrarca V, Della Torre A, Santolamazza F, Dolo G, Coulibaly M, Alloueche A, Curtis CG, Toure YT, Coluzzi M: The pyrethroid knock-down resistance gene in the Anopheles gambiae complex in Mali and further indication of incipient speciation within An. gambiae s.s. Insect Mol Biol 2003, 12:241-245.

18. Awolola TS, Brooke BD, Koekemoer LL, Coetzee M: Resistance of the malaria vector Anopheles gambiae s.s. to pyrethroid insecticides, in south-western Nigeria. Ann Trop Med Parasitol 2002, 96:849-852.

19. Oduola AO, Idowu ET, Oyebola MK, Adeogun AO, Olojede JB, Otubanjo OA, Awolola TS: Evidence of carbamate resistance in urban populations of Anopheles gambiae s.s. mosquitoes resistant to DDT and deltamethrin insecticides in Lagos, South-Western Nigeria. Parasit Vectors 2012, 5:116,

20. Hargreaves K, Koerkemoer LL, Brooke B, Hunt RH, Mthembu J, Coetzee M: Anopheles funestus resistant to pyrethroid insecticides in South Africa. Med Vet Entomol 2000, 14:181-189.

21. Etang J, Manga L, Chandre F, Guillet P, Fondjo E, Mimpfoundi R, Toto JC, Fontenille D: Insecticide susceptibility status of Anopheles gambiae s.l. (Diptera: Culicidae) in the Republic of Cameroon. J Med Entomol 2003, 40:491-497.

22. WHO: Recommandations de la consultation technique sur la lute contre les vecteurs du paludisme dans la Région africaine de l'OMS. Brazaville: Congo/ Rapport technique de I'OMS; 2011:2.

23. Scott J, Brogdon W, Collins F: Identification of single specimens of the Anopheles gambiae complex by PCR. Am J Trop Med Hyg 1993, 49:520-529.

24. Favia G, Lanfrancotti A, Spanos L, Siden-Kiamos I, Louis C: Molecular characterization of ribosomal DNA polymorphisms discriminating among chromosomal forms of Anopheles gambiae s.s. Insect Mol Biol 2001, 10:19-23.

25. Weill M, Lutfalla G, Mogensen K, Chandre F, Berthomieu A, Berticat C, Pasteur N, Philips A, Fort P, Raymond M: Insecticide resistance in mosquito vectors. Nature 2003, 423:136-137.

26. Raymond M, Rousset F: Genepop (version 1.2), population genetics software for exact tests and eucumenicism. J Heredity 1995, 86:248-249.

27. Goudet J, Raymond M, De Meeüs T, Rousset F: Testing differentiation in diploid populations. Genetics 1996, 144:1933-1940.

28. Akogbéto MC, Padonou GG, Gbénou D, Irish S, Yadouleton A: Bendiocarb, a potential alternative against pyrethroid resistant Anopheles gambiae in Benin, West Africa. Malaria J 2010, 9:204.

29. Padonou GG, Sezonlin M, Gbedjissi GL, Ayi I, Azondekon R, Djenontin A, Bio-Bangana S, Oussou O, Yadouleton A, Boakye D, Akogbeto M: Biology of Anopheles gambiae and insecticide resistance: Entomological study for a large scale of indoor residual spraying in South East Benin. J Parasitol Vector Biol 2011, 3(4):9-68.

30. Diabaté A, Baldet T, Chandre F, Akogbeto M, Guiguemde TR, Darriet F, Brengues C, Guillet P, Hemingway J, Small GJ, Hougard JM: The role of agricultural use of insecticides in resistance to pyrethroids in Anopheles gambiae s.l. in Burkina Faso. Am J Trop Med Hyg 2002, 67:617-622.

31. Weill M, Malcolm C, Chandre F, Mogensen K, Berthomieu A, Marquine M, Raymond M: The unique mutation in Ace-1 giving high insecticide resistance is easily detectable in mosquito vectors. Insect Mol Biol 2004, 13:1-7.

32. Djogbénou L, Chandre F, Berthomieu A, Dabiré R, Koffi A, Alou H, Weill M: Evidence of introgression of the ace- $1^{R}$ mutation and of the ace-1 duplication in West African Anopheles gambiae s.s. PLoS One 2008, 3(5):2172. 
33. Djogbénou L, Pasteur N, Bio-Bangana S, Baldet T, Irish SR, Akogbeto M, Weill M, Chandre F: Malaria vectors in the Republic of Benin: Distribution of species and molecular forms of the Anopheles gambiae complex. Acta Trop 2010, 114:116-122.

34. Asidi AN, N'Guessan R, Koffi AA, Curtis CF, Hougard JM, Chandre F, Darriet F, Zaim M, Rowland MW: Experimental hut evaluation of bednets treated with an organophosphate (chlorpyrifos-methyl) or a pyrethroid (lambdacyalothrin) alone and in combination against insecticide-resistant Anopheles gambiae s.s. and Culex quinquefasciatus mosquitoes. Malaria J 2005, 4:25.

35. Djogbénou L, Noel V, Agnew P: Costs of insensitive acetylcholinesterase insecticide resistance for the malaria vector Anopheles gambiae homozygous for the G119S mutation. Malaria J 2010, 9:12.

doi:10.1186/1756-3305-6-192

Cite this article as: Aïkpon et al: Bendiocarb resistance in Anopheles gambiae s.l. populations from Atacora department in Benin, West Africa: a threat for malaria vector control. Parasites \& Vectors 2013 6:192.

\section{Submit your next manuscript to BioMed Central and take full advantage of:}

- Convenient online submission

- Thorough peer review

- No space constraints or color figure charges

- Immediate publication on acceptance

- Inclusion in PubMed, CAS, Scopus and Google Scholar

- Research which is freely available for redistribution 